\title{
Review on Decision Support System Approach for Agriculture Field
}

\author{
Ms. Shweta C. Meshram ${ }^{1}$, Mr. A.D. Gawande ${ }^{2}$, Mrs. K.R. Ingole ${ }^{3}$ \\ Student, Department of Computer Science \& Engineering, Sipna COET, Amravati, Maharashtra, India ${ }^{1}$ \\ Professor, Department of Computer Science \& Engineering, Sipna COET, Amravati, Maharashtra, India ${ }^{2}$ \\ Assistant Professor, Department of Information Technology, Sipna COET, Amravati, Maharashtra, India ${ }^{3}$
}

\begin{abstract}
Decision Support Systems are computerized systems, which include models and databases and they are used in decision making. It has been applied to solve variety of agricultural problems. Process of taking a decision is so complex as there are several factors affecting entire farming process. The environmental data plays a vital role in agriculture decision, which changes at a rapid rate. Keeping these data updated can be done by using a Service Oriented Approach (SOA). At present, irrigation decision-making systems applied to the field of agriculture were mostly aimed at a given area and specific crops. It was difficult to be applied in different areas and different crops. In this paper, a precision irrigation decision-making system has done something to solve this problem. This paper presents that SOA used to get precise irrigation schedule for different crops. In addition, it shows a good reflection and wide use.
\end{abstract}

Keywords: Decision Support System (DSS), Service Oriented Approach (SOA).

\section{INTRODUCTION}

Decision support system (DSS) is a computerbased information system that supports business or organizational decision making activities. The decision support systems are present in many fields and aim to help the decision maker in his task by providing him all the relevant elements for decision making.

There are several problems related to agriculture like crop management, inadequate use of manures and fertilisers, inadequate water suppy, quality of seeds, etc. But water scarcity and competition is the main issue in developing countries as far as water resources development and management is concerned. The per capita availability of water is decreasing day by day due to population growth. The demand for water is rising for increased food production, further industrial development, better standards of living, etc. Due to the scarcity of water, and the attention of decision makers to the optimum use of the water this leads to maximize the benefit. DSS using databases, human-machine to combine a large number of models realizes scientific decision making.

The decision support systems are present in many fields and aim to help the decision maker in his task by providing him all the relevant elements for decision making.[13] Decision support systems in irrigation management applications began in the early 1990s [1]. Management of irrigation is one of the most important aspects of cultivation production. Farmers do not have the needed information to minimize water usage without reducing plant productivity. Optimize the irrigation water usage need an expert to provide farmers by the exact needed water at exact time to irrigate their crops. These experts are rare to found when farmers needed. Also, it doesn't easy to found them in all villages.
Using information and communication technology to develop systems that manage water usage will help in enhancing the irrigation water usage efficiency. This technology can be used to transfer knowledge from irrigation experts to both agricultural engineers/officers and farmers which lead to enhance water usage [11]. In this system the amount of water applied is determined dependent on each user situation and this system can use to build a decision-making model to irrigation for different users.

\section{RELATED WORK}

Irrigation water is the most limiting and most precious resource of agriculture today. Managing irrigation precisely is one of our most urgent challenges [3]. Too little water, even for a short time, can damage a crop, reduce yield and quality, and destroy a farmer's income. Too much water is expensive, wasteful, and raises environmental concerns raise the rate of groundwater and surface water that destroys farmland. Recently many researchers interested in studying DSS and the integration between Service Oriented Architecture (SOA) and DSS in agricultural domain and others.

Ayman Nada, Mona Nasr and Marwa Salah in [1]have discussed a technique for irrigation decision-making systems applied in agriculture which is useful for given area and specific crops; it is difficult to be applied in different areas and different crops. In addition, the system is mostly based on networks and results are shown in the form of a web. Business handling logic and decisionmaking logic are often solidified in code, various 
processes closely coupled [2]. DSS consists of five components model are Data Management DMS, Model Management MMS, Knowledge-based Management KB, User Interface - Graphical User Interface (GUI), and The User which consider a decision makers or manager as in $(1)[4,5]$.

The data management system DMS performs the function of storing and maintaining the information that you want DSS to use. The model management system MMS stores and maintains the DSS models. Its function of managing models is similar to that of a database management system. The model management component cannot select the best model for you to use for a particular problem that requires your expertise but it can help you to create and manipulate models quickly and easily.

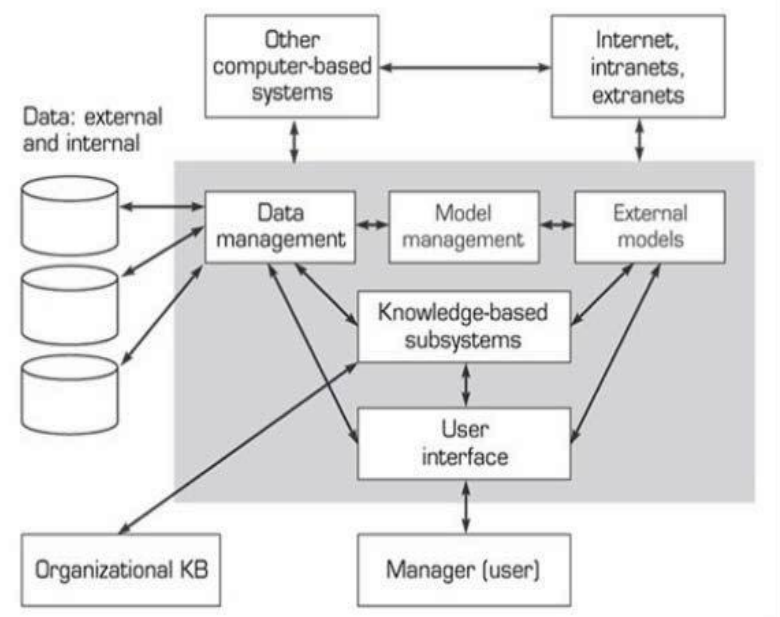

Fig.1 DSS Components

The knowledge management system KBS, provides information about the relationship among data that is too complex for a database to represent. It consists of rules that can constrain possible solution as well as alternative solutions and methods for evaluating them like that in an expert system [6]. The user interface management component allows you to communicate with the DSS. It consists of the user interface management system.

The purpose of irrigation scheduling is to determine the exact amount of water to apply to the field and the exact timing for application. The amount of water applied is determined by using a criterion to determine irrigation need and a strategy to prescribe how much water to apply in any situation [7]. Precise irrigation decision support systems adopt advanced SOA framework ideas to realize the irrigation decision-making process, connecting resources according to the needs as (2). It designs function modules during the process of irrigation as services which can be called by this system and also used by other members of the network. The service is put in a precision agriculture integration platform service registration center Universal Description, Discovery and Integration (UDDI) [7]

\section{PROPOSED WORK}

In our work we have to proposed a system to optimize crop water usage by using SOA technology. This system can be proved helpful for farmers to irrigate their crops. It will be applied in agriculture which is useful for different areas and different crops. The work presents a generic design for irrigation expert system for trees which provides the farmers by the irrigation expertise to determine the exact water needed at exact time according to their environment.

To obtain our goal, DSS architecture is based on SOA. SOA enable proposed architecture to the aspects: flexibility, performance and efficiency are directly effects on the quality of service. SOA have well-designed services in order to gain the predicted benefits, like flexible business processes and low development costs. Although individual service efficiency is high, but from the business sense, completing a business task requires more service calls, like calculation of irrigation schedule, so the corresponding times of requesting and responding will increase.

Following is the use case diagram of the proposed system-

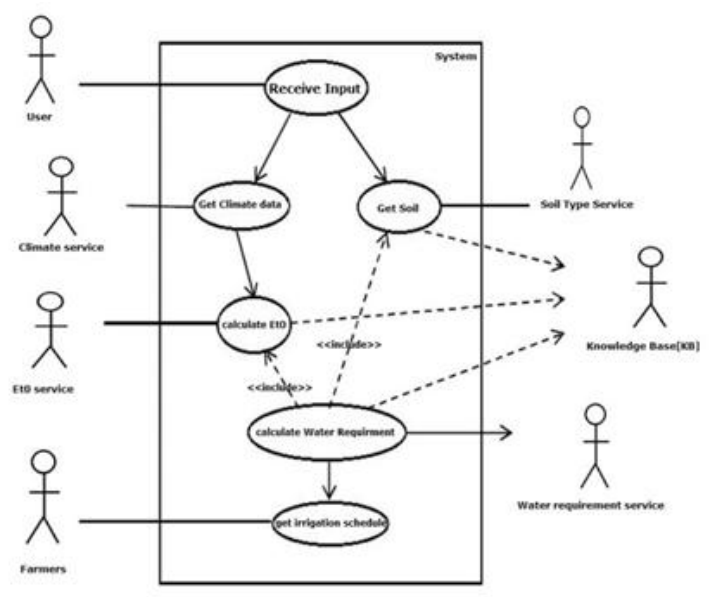

Fig. 2 Use case diagram of proposed system

It will obtain soil information on the basis of certain parameters and provide real time information about irrigation schedule. It also provide cropping plant, requisite fertilizers on the basis of current natural situation to farmers.

To generic design DSS model components using SOA that:

A. Data Management System

The DMS component includes the irrigation model task which manages all the system components.

B. Model Management System

The Model Management System is executed by using SOA. SOA have well-designed services in order to gain the predicted benefits, like flexible business processes and low development costs. The business logic is more 
complex and need more functions that effects on again consolidated information from farmer will help to increasing service size. The DSS design using SOA model show recommended results to other farmers so that comprised of the following layers as (3):

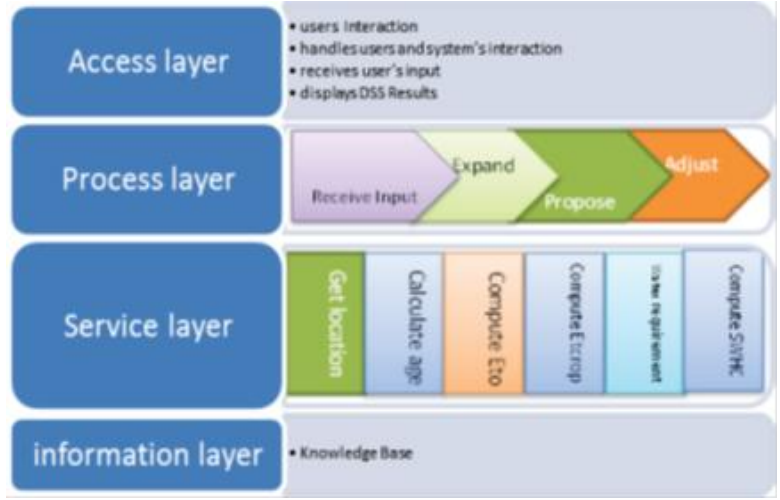

Fig. 3 SOA system layer

\section{Access layer}

The access layer contains the user interface, manages access to system resources and it will display irrigation schedule.

\section{Process layer}

The process layer supports business processes and application workflows.

\section{Service layer}

Service layer contains the application functionality that imports the business process model and integrates it with the corresponding logic business process.

\section{Information layer}

Information layer represents the Knowledge base (KB) data sources and data definitions.

\section{Knowledge Based System}

The KBS represents the irrigation system knowledge base which is built from the development generic design in Central Laboratory for Agricultural Experts Systems (CLAES). This KBS is acquired from irrigation experts for irrigate crops.

\section{User Interface}

User interface using application that using services model to display irrigation schedule.

Propose task aims to compute the proposed irrigation schedule. The needed water in each plant stage will be calculated according to the user specific situation which determined in the previous subtask. It uses three inference steps namely: get ET0 service, get Etcrop service and get water requirement service.

The farmer will give information about the soil parameters and system will provide the soil type with better crop to be yield. It will also intimate farmer about fertilizers to be used. With this information, farmer will confirm and so demand supply can also be maintained in the future.

\section{CONCLUSION}

The goal of this irrigation system is to determine the exact amount of needed water and the exact timing for applying it. The amount of water required will be determined dependent on each user situation. The system will be used to build a decision-making model for irrigation for different users. This is focused only on services and the system assembly model, which leads to a good reflection, wide usability and save time.

\section{ACKNOWLEDGEMENT}

I would like to express my gratitude and appreciation to all those who helped me to complete this paper. A special thanks to my guide, Mr. Avinash D. Gawande, Mrs. Ketki R. Ingole whose help, stimulating suggestions and encouragement helped me in writing this paper. At last, I am thankful to my family \& friends whose encouragement and constant inspiration helped me to complete this paper work verbally and theoretically.

\section{REFERENCES}

[1] Ayman Nada, Mona Nasr, Marwa Salah "Service oriented approach for decision support systems" Information Technology and Artificial Intelligence Conference (ITAIC), 2014 IEEE 7th Joint International

[2] J. Shim, M.Warkentin, J. Courtney, D. Power, R. Sharda, and C.Carlsson, "Past, present, and future of decision support technology". Decision Support Systems, vol. 33, no.2, pp. 111-126, Elsevier, 2002.

[3] J. Cheng, K. Law, H. Bjornsson, A. Jones, and R. Sriram, "A service oriented framework for construction supply chain integration", Automation in Construction, pp. 245-260, 2010.

[4] M. Mahmoud, and I. Hassan, "An Integrated Expert System and Gedgraphical Information System in Agriculture Domain", the Third National GIS Symposium, Saudi Arabia, April 07 - 09, 2008.

[5] Turban, and J. Aronson, "Decision Support Systems and Intelligent Systems".Prentice Hall, 2001.

[6] Turban, J. Aronson, and T. Liang, "Decision Support Systems and Intelligent Systems", Prentice Hall, 2005.

[7] U. ftikhar, and Sikder, "Knowledge-based spatial decision support systems: An assessment of environmental adaptability of crop", Expert Systems with Applications, vol. 36, no. 3, pp. 5341-5347, 2009

[8] X. Liyuan, C. Liping, C. Tainan, and G. Yunbing, "SOA-based precision irrigation decision support system", Mathematical and Computer Modelling, pp. 944-949, 2011.

[9] CLAES, "Irrigation Design Expert Systems for CITIX", Giza, Egypt,Tech. Rep. TR-CLAES-228-2001.11, Nov. 2011.

[10] CLAES, "Irrigation Design Expert Systems for Mango", Giza, Egypt, Tech. Rep. TR-CLAES-268-2003.7, Jul. 2003.

[11] CLAES, "KSR Tool Code Documentation", Giza, Egypt, Tech. Rep. TR-CLAES-263-2003.4, Apr. 2003.

[12] Nada, M. Nasr, and M. Hazman, "Irrigation Expert System for Trees", International Journal of Engineering and Innovative Technology (IJEIT), vol. 3, no. 8, pp. 170-175, Feb.2014.

[13] R. Allen, L. Pereira, D. Raes, and M. Smith, "Crop evapotranspiration-Guidelines for computing crop water requirements", FAO Irrigation and Drainage, no. 56, FAO, Rome, $300,6541,1998$. 
[14] Fatima Boumahdi, a Rachid Chalal "A New Decision Support System Based on Agents Dedicated to Service-Oriented Architectures", AASRC, Vol. 4, No. 5, Sept 2012

\section{BIOGRAPHIES}

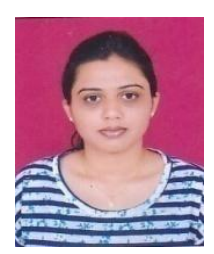

Shweta C. Meshram received her B.E. degree in Computer Science \& Engineering from Amravati University. She is currently pursuing her Post Graduation in Computer Engineering from Sipna COET, Amravati.

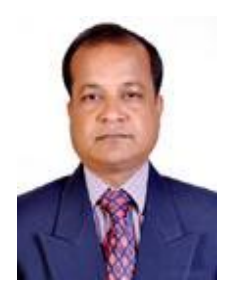

Avinash D. Gawande received his PhD. $\mathrm{He}$ is working as professor \& head in the Department of Computer Science \& Engineering at Sipna COET, Amravati. $\mathrm{He}$ has $21 \mathrm{yrs}$ teaching experience. His areas of interest are Signal Processing, Information Storage and Data Recovery.

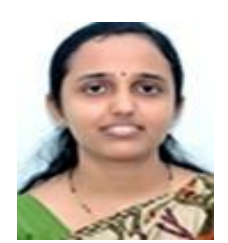

Ketki R. Ingole received her M.E. degree in Computer Science \& Engineering. She is working as assistant professor \& has 9 yrs teaching experience. Her areas of interest are Internet Technology, Computer Architecture and Organization and OOP. 